\title{
Determination of Asymmetric Dimethylarginine and Symmetric Dimethylarginine in Biological Samples of Mice Using LC/MS/MS
}

\author{
Daisuke Saigusa $^{1}$, Mai Takahashi ${ }^{1}$, Yoshitomi Kanemitsu ${ }^{1}$, Ayako Ishida ${ }^{1}$, Takaaki Abe ${ }^{2}$, \\ Tohru Yamakuni ${ }^{3}$, Naoto Suzuki ${ }^{1}$, Yoshihisa Tomioka ${ }^{{ }^{*}}$ \\ ${ }^{1}$ Laboratory of Oncology, Pharmacy Practice and Sciences, Graduate School of Pharmaceutical Sciences, \\ Tohoku University, Sendai, Japan \\ ${ }^{2}$ Division of Medical Sciences, Graduate School of Biomedical Engineering, Tohoku University, Sendai, Japan \\ ${ }^{3}$ Department of Pharmacotherapy, Graduate School of Pharmaceutical Sciences, Tohoku University, Sendai, Japan \\ E-mail: ytomioka@mail.pharm.tohoku.ac.jp \\ Received March 7, 2011; revised April 2, 2011; accepted April 30, 2011
}

\begin{abstract}
Herein, we present a novel method of asymmetric dimethylarginine (ADMA) and symmetric dimethylarginine (SDMA) determination within biological samples using protein precipitation and LC/MS/MS. Chromatographic separation of ADMA and SDMA was successfully performed using a silica column with optimized elution, or mobile phase, of $10 \mathrm{mM}$ ammonium acetate buffer $\mathrm{H}_{2} \mathrm{O}$ /methanol/acetonitrile (20/35/45, v/v) at $\mathrm{pH}$ 4. The calibration ranges were $0.50-50.0 \mu \mathrm{g} \cdot \mathrm{mL}^{-1}$, and good linearities were obtained for all compounds $(r$ > 0.99). The intra- and inter-assay accuracies with recoveries and precisions at three concentration levels (i.e. $1.00,5.00$ and $25.0 \mu \mathrm{g} \cdot \mathrm{mL}^{-1}$ ) were better than $86.9 \%$ and $7.36 \%$, respectively. The analytical performance of the method was evaluated by determination of compounds in plasma, urine and tissues from male $\mathrm{BALBc} / \mathrm{J}$ mice. For the first time, we were able to characterize the distribution of ADMA, SDMA and ADMA/SDMA in plasma, urine, brain, heart, kidneys, liver, lungs, pancreas and spleen. Additionally, we demonstrated that the ADMA/SDMA ratio in the brain was approximately 10-fold lower than all the other biological samples. Only $10 \mu \mathrm{L}$ of plasma, $1 \mu \mathrm{L}$ of urine and about $25 \mathrm{mg}$ of tissues were required. These results suggest that the developed methodology was useful in ADMA and SDMA determination within biological samples.
\end{abstract}

Keywords: Asymmetric Dimethylarginine, Symmetric Dimethylarginine, Creatinine, Arginine, Tissue, Liquid Chromatography/Tandem Mass Spectrometry.

\section{Introduction}

Asymmetric dimethylarginine (ADMA) and symmetric dimethylarginine (SDMA) are methylated by protein arginine (Arg) methyltransferases (PRMTs) from Arg and metabolized by dimethylarginine dimethylaminohydrolase (DDAH) (Figure 1) [1,2]. ADMA and SDMA are endogenous uremic toxins that are associated with chronic kidney disease (CKD) and renal inflammation [3-6]. In fact, Toyohara, et al. reported that ADMA was a biomarker for CKD patients [7]. In previous studies, the biological reactions associated with these conditions have been primarily attributed to ADMA, whereas the role of SDMA has been overlooked. However, it has recently been reported that a ratio of Arg, ADMA and SDMA is important in the pathophysiological analysis of cardiovascular diseases, reduced renal functions and other diseases $[6,8,9]$. Therefore, a methodology for detecting both ADMA and SDMA is warranted. The analytical methods of ADMA and SDMA have been developed using several techniques. The enzyme-linked immunosorbent assay (ELISA) method has been shown to detect cross-reactivity with SDMA [10], albeit with low sensitivity. Given that ADMA and SDMA are structural isomers and the molecular weight is identical at 202.1, chromatographic separation using high performance liquid chromatography (HPLC) with ultra violet (UV), radioimmunoassay and fluorescence (FL) detection was 
shown to be necessary [11-15]. The first HPLC method for dimethylarginine detection was reported in 1999 [12]. In 2000, an HPLC method with FL detection was developed, which had high sensitivity, reliability, and good separation of ADMA and SDMA [13,15]. Unfortunately, these HPLC methods are very time consuming. Since 2000, ADMA and SDMA have also been detected by liquid chromatography/mass spectrometry (LC/MS) and liquid chromatography/tandem mass spectrometry (LC/ MS/MS) [16-21]. Although detection of a selective product ion with MS/MS fragmentation can be difficult, Bishop, et al. and Zotti, et al. have been reported that the selective product ions for ADMA and SDMA are at $\mathrm{m} / \mathrm{z}$ $203 \rightarrow 46$ and $203 \rightarrow 172$, respectively [17-19]. Additionally, though these methods are more sensitive, ADMA and SDMA have the different pattern of dissociation using various MS system. Di Gangi, et al. have developed a reliable method using ultra per-formance LC/MS /MS that is simple and has a short analytical time [21]. This method is sensitive, however preparation for derivatization is time consuming, and ADMA and SDMA have not been separated successfully. The use of capillary electrophoresis (CE) for ADMA and SDMA analysis has also been reported. In fact, recent reports describe using CE/MS/MS and CE/UV for determination of ADMA and SDMA [22,23]. Due to the high number of theoretical plates, these methods have good separation of ADMA and SDMA, high sensitivity and reliability. However, CE is only appropriate for determining ADMA and SDMA in plasma (i.e. it is not applicable in tissues or any biological samples). Additionally, homoarginine is not a suitable internal standard (IS) because it is detected in biological samples. Thus, a simple, un-deriva- tive, highly sensitive and reliable method using LC/MS /MS for ADMA and SDMA determination, which can also separate isomers and determine ADMA and SDMA in biological samples, is warranted. The purpose of the present study is to: 1) develop a simple, sensitive and reliable method for ADMA, SDMA, Arg and creatinine (Cr) determination in plasma, urine and tissues, and 2) to determine the distribution of ADMA and SDMA in biological samples of mice. Herein, we have described the chromatographic separation of ADMA and SDMA following HPLC optimization.

\section{Experimental}

\subsection{Chemicals}

An ADMA standard was obtained from Sigma-Aldrich (St. Louis, MO). SDMA and Cr standards were obtained from Wako Pure Chemical Industries (Tokyo, Japan). Arg and L-arginine- ${ }^{13} \mathrm{C}_{6}$ hydrochloride $\left(\right.$ Arg- $-{ }^{13} \mathrm{C}_{6}$ ) were obtained from Tokyo Chemical Industry (Tokyo, Japan) and Cambridge Isotope Laboratories (Andover, MA), respectively. Creatinine- $\mathrm{d}_{3}$ (methyl- $\left.\mathrm{d}_{3}\right)\left(\mathrm{Cr}-\mathrm{d}_{3}\right)$ was obtained from Toronto Research Chemicals (North York, Ontario, Canada). Methanol (MeOH) and acetonitrile $\left(\mathrm{CH}_{3} \mathrm{CN}\right)$ of LC/MS grade were obtained from Kanto Chemical (Tokyo, Japan). Ammonium acetate

$\left(\mathrm{CH}_{3} \mathrm{COONH}_{4}\right)$, acetic acid $\left(\mathrm{CH}_{3} \mathrm{COOH}\right)$ and formic acid $(\mathrm{HCOOH})$ of LC/MS grade were obtained from Wako Pure Chemical Industries. Ultrapure-grade water was prepared with Purelab Ultra from Organo (Tokyo, Japan).

\subsection{Mass spectrometry system and conditions}

The MS system was a Thermo Fisher Scientific TSQ Quantum Ultra triple quadrupole mass spectrometer equipped with a heated electrospray ionization (HESI) source. The operating conditions were optimized for each compound by continuously infusing standard solutions dissolved in water $\left(10.0 \mu \mathrm{g} \cdot \mathrm{mL}^{-1}\right)$ at a rate of 5 $\mu \mathrm{L} \cdot \mathrm{min}^{-1}$. Our final analytical conditions for MS are summarized in Table 1. HESI was performed in a positive ion mode (pos) for ADMA, SDMA, Arg, Cr, IS1 and IS2. Samples were analyzed using the selected reaction monitoring (SRM) mode, and employing the transition of the $(\mathrm{M}+\mathrm{H})^{+}$precursor ions to their product ions. The MS/MS transitions were determined in the full scan mode ( $\mathrm{m} / \mathrm{z} 30$ - 250). For the MS/MS analysis, the optimized tube lens offsets and collision energies for collision-induced dissociation (CID) of ADMA, SDMA, Arg, Cr, IS1 and IS2 are summarized in Table 1. The pos HESI spray voltages were $1,500 \mathrm{~V}$, the heated capillary temperature was $380^{\circ} \mathrm{C}$, the sheath gas pressure was 65 psi, the auxiliary gas setting was 20 psi and the heated vaporizer temperature was $380^{\circ} \mathrm{C}$. Both the sheath gas and auxiliary gas were nitrogen gas. The collision gas was argon at a pressure of 1.2 mTorr. The LC/MS/MS

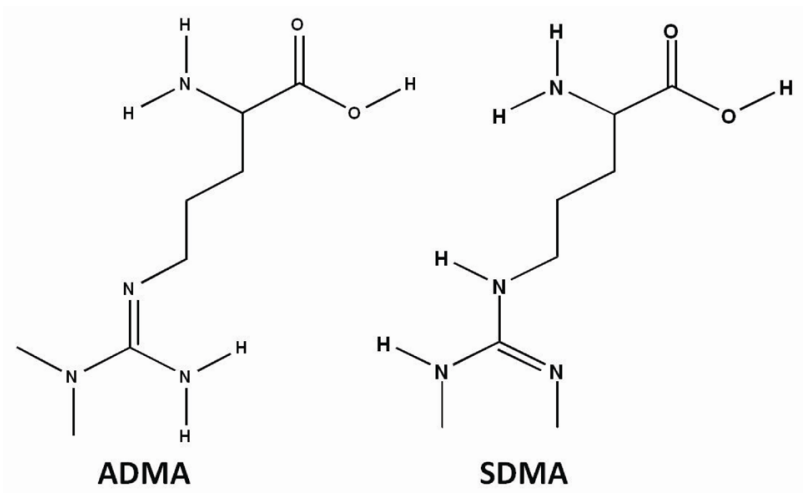

Figure 1. Chemical structure of asymmetric dimethyl arginine (ADMA) and symmetric dimethyl arginine (SDMA). 
Table 1. Analytical conditions of HPLC and MS systems for determining ADMA, SDMA, Arg and Cr.

\begin{tabular}{|c|c|}
\hline HPLC system & NANOSPACE SI-2 (Shiseido) \\
\hline Analytical column & Mightysil Si 60 (250 × 3 mm I.D., 5 нm particle size $)$ \\
\hline Guard column & CAPCELLPAK C18 MGII ( $10 \times 2$ mm I.D., $3 \mu \mathrm{m}$ particle size $)$ \\
\hline Mobile phase & $10 \mathrm{mM} \mathrm{CH}_{3} \mathrm{COONH}_{4}-\mathrm{H}_{2} \mathrm{O} / \mathrm{MeOH} / \mathrm{CH}_{3} \mathrm{CN}=20 / 35 / 45(\mathrm{pH}=4)$ \\
\hline Flow rate & $400 \mu \mathrm{L} \cdot \min ^{-1}$ \\
\hline Oven temperature & $40^{\circ} \mathrm{C}$ \\
\hline Divert valve & 0 - 4 min: waste, 4 - 14.5 min: detector, 14.5 - 15 min: waste \\
\hline MS system & TSQ quantum ultra (Thermo Fisher Scientific) \\
\hline Ionization & $\operatorname{HESI}(+)$ \\
\hline Spray voltage & $1500 \mathrm{~V}$ \\
\hline Vaporizer temperature & $380^{\circ} \mathrm{C}$ \\
\hline Sheath gas pressure & 65 psi \\
\hline Auxiliary gas pressure & 20 psi \\
\hline Capillary temperature & $380^{\circ} \mathrm{C}$ \\
\hline Collision gas pressure & 1.2 mTorr \\
\hline Tube lens offset & ADMA, SDMA: 64, Arg: 54, Cr: 55, IS1: 54 and IS2: 55 \\
\hline Collision energy & 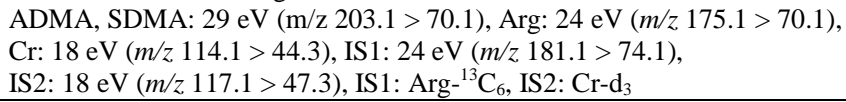 \\
\hline
\end{tabular}

system was controlled by the Xcalibur software (Thermo Fisher Scientific, San Jose, CA) and data were collected with the same software.

\subsection{Liquid chromatography system and condi- tions}

A NANOSPACE SI-2 LC system comprising an LC pump, auto-sampler, column oven and on-line degasser (Shiseido, Tokyo, Japan) was used. The separations were performed on a Mightysil Si $(250 \mathrm{~mm} \times 2 \mathrm{~mm}$ I.D., $5 \mu \mathrm{m}$ particle size) analytical column coupled with a CAPCELL PAK C18 MG II $(10 \mathrm{~mm} \times 2 \mathrm{~mm}$ I.D., $3 \mu \mathrm{m}$ particle size) (Shiseido, Tokyo, Japan) guard column maintained at $40^{\circ} \mathrm{C}$ (Table 1). The effect of the ratio of organic solution in mobile phase on retention was tested by varying the percentage of $\mathrm{MeOH}$ and $\mathrm{CH}_{3} \mathrm{CN}$. The percentages of $\mathrm{MeOH}$ and $\mathrm{CH}_{3} \mathrm{CN}$ were $10,20,30,40,50$, 60,70 and $80 \%$ while keeping the $\mathrm{CH}_{3} \mathrm{COONH}_{4}$ concentration constant at $10 \mathrm{mM}$ in the mobile phases. The mixture of $\mathrm{MeOH}$ and $\mathrm{CH}_{3} \mathrm{CN}$ was as follows: $10 \mathrm{mM}$ $\mathrm{CH}_{3} \mathrm{COONH}_{4}-\mathrm{H}_{2} \mathrm{O} / \mathrm{MeOH} / \mathrm{CH}_{3} \mathrm{CN}$. MeOH and $\mathrm{CH}_{3} \mathrm{CN}$ ratios were varied between 10 and $80 \%$ while keeping $\mathrm{H}_{2} \mathrm{O}$ at $20 \%$. The $\mathrm{pH}$ of the mobile phase was between 3.5 and 6.7, and the flow rate was between 300 and 1000 $\mu \mathrm{L} \cdot \mathrm{min}^{-1}$. Retention time (R.T.) and resolution (Rs) values were used to evaluate the retention and separation of ADMA and SDMA, and the R.T. and Rs values of ADMA and SDMA were plotted against the content of $\mathrm{MeOH}$ and $\mathrm{CH}_{3} \mathrm{CN}$ in the mobile phase. The Rs value was calculated from equation mentioned below:

$$
\text { Rs }=\frac{(\text { R. T. of ADMA })-(\text { R. T. of SDMA })}{0.5 \times(\text { half-width of ADMA })+(\text { half-width of SDMA })}
$$

\subsection{Calibration}

All peaks were integrated automatically by the Xcalibur software. The ADMA, SDMA and Arg amounts were calculated from the calibration curves using the ratios of their peak areas to that of IS1, and the Cr amounts were calculated from the calibration curve using the ratios to IS2. The range used for the calibration curves of ADMA, SDMA, Arg and $\mathrm{Cr}$ was between $0.500-50.0 \mu \mathrm{g} \cdot \mathrm{mL}^{-1}$ (i.e. 2.47 - 247, 2.47 - 247, 2.87 - 287 and $4.42-442$ $\mu \mathrm{mol} \cdot \mathrm{L}^{-1}$, respectively).

\subsection{Validation of the analytical method}

To determine the accuracy and precision, the newly developed method was validated at three concentrations $\left(1.00,5.00\right.$ and $\left.25.0 \mu \mathrm{g} \cdot \mathrm{mL}^{-1}\right)$ using five samples on three different days. The accuracies and precisions of the method were determined through intra- and inter-day analyses. Accuracy was calculated from the percentage deviation from the mean of the true value, and precision was expressed as the relative error and coefficient of variation (CV, \%). The data were validated based on FDA's Guidance for Industry: Bioanalytical Method Validation guidelines.

\subsection{Animals and collection of biological samples}

Male BALBc/J mice ( $n=3$ ) were kept in a room with a 12-h/12-h light-dark cycle (light cycle from 9:00 to $21: 00)$ at $23^{\circ} \mathrm{C}-25^{\circ} \mathrm{C}$ and provided water and food ad libitum. All procedures used for LC/MS/MS were approved by the committee on the Care and Use of Experimental Animals, Tohoku University, in accordance with the Guide for the Care and Use of Laboratory Animals published by the U.S. National Institutes of Health. To demonstrate the biological distribution of ADMA and SDMA, we collected 9 biological samples (plasma, urine and 7 tissues). Mice were first anesthetized with so- 

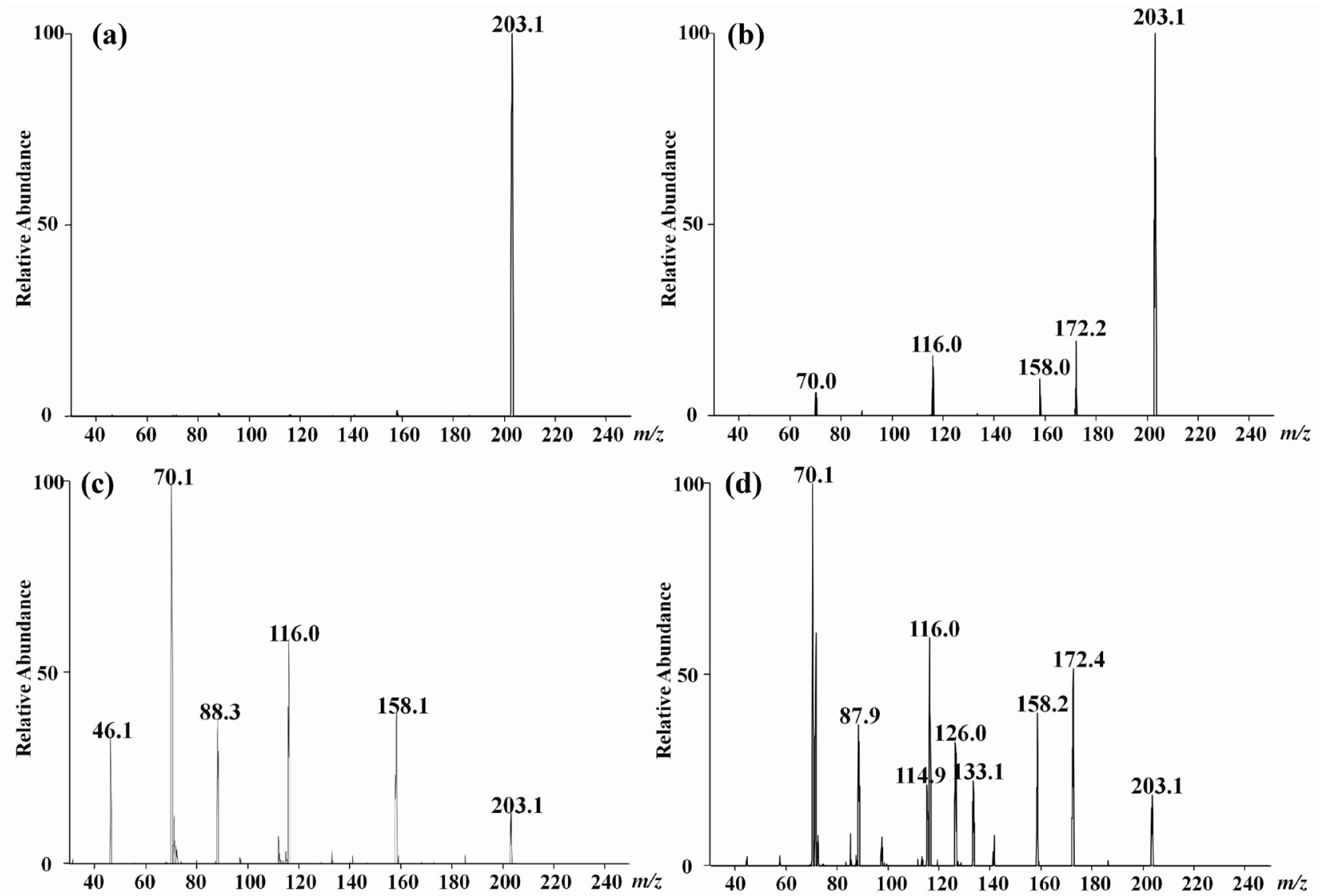

Figure 2. Precursor ion mass spectra of ADMA (a) and SDMA (b), and product ion mass spectra of ADMA (c) and SDMA (d).

dium pentobarbital. Blood was then collected via retroorbital bleeding, transferred into a $1.5-\mathrm{mL}$ plastic tube with $30 \mu \mathrm{L}$ of $10 \mathrm{mM}$ ethylenediaminetetraacetic acid, immediately centrifuged at $16,400 \times g$ for $10 \mathrm{~min}$, and the supernatant was transferred into a new plastic tube. Mice were then rapidly perfused transcardially with cold saline through the left ventricle and thereby sacrificed. Subsequently, urine and tissues (brain, liver, kidneys, lungs, pancreas, spleen and heart) were quickly removed. All plasma, urine and pulverized tissues were stored at $-80^{\circ} \mathrm{C}$.

\subsection{Sample preparation of plasma and urine}

Sample preparation of plasma and urine for LC/MS/MS was performed as follows. Plasma $(10 \mu \mathrm{L})$ and urine (1 $\mu \mathrm{L}$ ) were transferred into a $1.5-\mathrm{mL}$ plastic tube. Then, 50 $\mu \mathrm{L}$ of internal standard 1 (IS1; Arg- ${ }^{13} \mathrm{C}_{6}$ at $10 \mu \mathrm{g} \cdot \mathrm{mL}^{-1}$ ) and IS2 $\left(\mathrm{Cr}^{-\mathrm{d}_{3}}\right.$ at $\left.1 \mu \mathrm{g} \cdot \mathrm{mL}^{-1}\right)$, and $250 \mu \mathrm{L}$ of $0.1 \%$ $\mathrm{HCOOH} / \mathrm{CH}_{3} \mathrm{CN}$ were added. The resulting mixture was homogenized for $30 \mathrm{~s}$ in an ultrasonic bath. After centrifugation at $16,400 \times g$ for $10 \mathrm{~min}$, the supernatant was transferred into a new plastic tube and evaporated at $60^{\circ} \mathrm{C}$ until dry under nitrogen gas stream. The residue was reconstituted in $50 \mu \mathrm{L}$ of mobile phase, vortexed for $30 \mathrm{~s}$, and passed through a filter (pore size: $0.2 \mu \mathrm{m}$, YMC). Subsequently, $1 \mu \mathrm{L}$ of the filtered solution was injected into the LC/MS/MS system for analysis. The concentrations of the individual compounds were calculated from a regression of the calibration curves. The values were calculated as the mean \pm standard deviation (SD). Cr was used as a biomarker to correct for different volumes or urine produced per day [24]. The corrected values of ADMA, SDMA and Arg in urine were calculated by the concentration ratios of the individual compounds $\left(\mu \mathrm{g} \cdot \mathrm{mL}^{-1}\right)$ to the Cr concentration in urine $\left(\mu \mathrm{g} \cdot \mathrm{mL}^{-1}\right)$.

\subsection{Sample preparation of tissues}

For LC/MS/MS analysis, tissue preparation based on previously described methodology [25]. Approximately $25 \mathrm{mg}$ of each tissue was transferred into a 2-mL plastic tube, and $1000 \mu \mathrm{L}$ of $0.1 \% \mathrm{HCOOH} / \mathrm{CH}_{3} \mathrm{CN}, 50 \mu \mathrm{L}$ of internal standard 1 (IS1; Arg- ${ }^{13} \mathrm{C}_{6}$ at $10 \mu \mathrm{g} \cdot \mathrm{mL}^{-1}$ ) and IS2 $\left(\mathrm{Cr}-\mathrm{d}_{3}\right.$ at $\left.1 \mu \mathrm{g} \cdot \mathrm{mL}^{-1}\right)$ were added. The resulting mixture was homogenized for $30 \mathrm{~s}$ by a sonicator. After centrifu- 

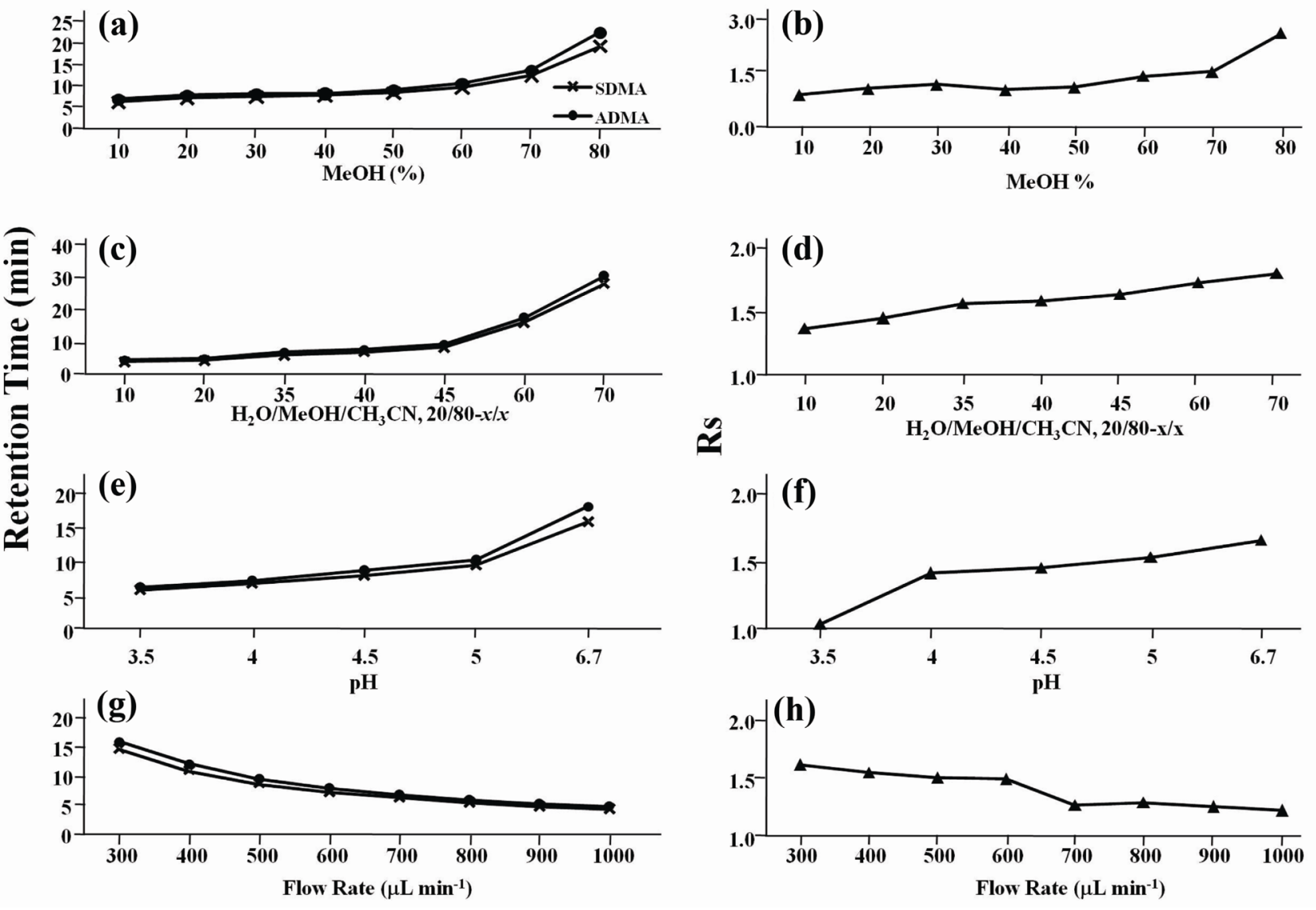

Figure 3. Effect of $\mathrm{MeOH}$ percentage in mobile phase $\left(\mathrm{H}_{2} \mathrm{O} / \mathrm{MeOH}\right)$ on retention time (R.T.) and resolution (Rs) (a, b) for ADMA and SDMA. Effect of $\mathrm{CH}_{3} \mathrm{CN}$ percentage in mobile phase $\left(\mathrm{H}_{2} \mathrm{O} / \mathrm{MeOH} / \mathrm{CH}_{3} \mathrm{CN}\right)$ on R.T. and Rs (c, d). Effect of pH on R.T. and Rs (e, f). Effect of flow rate on R.T. and Rs (g, h).

gation at $16,400 \times g$ for $10 \mathrm{~min}$, the supernatant was transferred into a new plastic tube and the preparations were following as described above.

\subsection{Statistical analyses}

For statistical analysis, we use Microsoft Office Excel 2007 software. The values were calculated as the mean \pm SD.

\section{Results and discussions}

\subsection{MS/MS and LC optimization}

The ionization of ADMA, SDMA, Arg and Cr was performed in positive ion mode. The optimized HESI of ADMA, SDMA, Arg, Cr, IS1 and IS2 produced abundant $[\mathrm{M}+\mathrm{H}]^{+}$ions at $\mathrm{m} / \mathrm{z}$ 203.1, 203.1, 175.1, 114.1, 181.1 and 117.1, respectively. The conditions for MS/ MS detection were optimized for maximum product ion formation through infusion analyses. The precursor and product ion mass spectra of ADMA and SDMA in a product ion scan mode were shown in Figure 2. The selective product ion of ADMA and SDMA that has the highest intensity from the precursor ion was the same at $\mathrm{m} / \mathrm{z} \quad 203.1 \rightarrow 70.1$. Martens-Lobenhoffer et al. reported the collision induced dissociation (CID) process of ADMA and SDMA [26], and some pervious methods selected different product ion $[18,19]$. In our MS system, the product ions were as follows: $\mathrm{m} / \mathrm{z} 40.1$ for ADMA and $m / z 129.1$ for SDMA. However, these ions were not selective and not the highest ions for ADMA and SDMA determination. Consequently, a chromatographic separation of ADMA and SDMA was necessary in our study. Quantification analyses were performed in the SRM mode owing to the high selectivity and sensitivity of SRM data acquisition, in which transitions from the precursor ion into the product ion were monitored at: $\mathrm{m} / \mathrm{z}$ $203.1 \rightarrow 70.1$ for ADMA and SDMA; $m / z$ 175.1 $\rightarrow 70.1$ for $\mathrm{Arg} ; \mathrm{m} / \mathrm{z} 114.1 \rightarrow 44.3$ for $\mathrm{Cr} ; \mathrm{m} / \mathrm{z} 181.1 \rightarrow 74.1$ for IS1; and $\mathrm{m} / \mathrm{z} 117.1 \rightarrow 47.3$ for IS2.

The results of retention and chromatographic separation are shown in Figure 3. Previously, Paglia, et al. described chromatographic separation techniques for 
Table 2. Linearity and correlation coefficients of ADMA, SDMA, Arg and Cr.

\begin{tabular}{cccc}
\hline & Calibration range & Equaition $^{\text {a }}$ & Correlation coefficient \\
\hline & & & \\
ADMA & $0.50-50.0 \mu \mathrm{g} \cdot \mathrm{mL}^{-1}\left(2.86-286 \mu \mathrm{mol} \cdot \mathrm{L}^{-1}\right)$ & $y=0.30 x+0.040$ & $r=0.998$ \\
SDMA & $0.50-50.0 \mu \mathrm{g} \cdot \mathrm{mL}^{-1}\left(4.27-427 \mu \mathrm{mol} \cdot \mathrm{L}^{-1}\right)$ & $y=0.67 x+0.014$ & $r=0.996$ \\
Arg & $0.50-50.0 \mu \mathrm{g} \mathrm{mL} \mathrm{mL}^{-1}\left(2.87-287 \mu \mathrm{mol} \cdot \mathrm{L}^{-1}\right)$ & $y=0.12 x-0.013$ & $r=0.999$ \\
Cr & $0.50-50.0 \mu \mathrm{g} \cdot \mathrm{mL}^{-1}\left(4.42-442 \mu \mathrm{mol} \cdot \mathrm{L}^{-1}\right)$ & $y=0.82 x+0.018$ & $r=0.999$ \\
\end{tabular}

a. $x$, analyte concentration $\left(\mu \mathrm{mol} \cdot \mathrm{L}^{-1}\right) ; y$, peak area ratio

Table 3. Accuracy of determination method for ADMA, SDMA, Arg and Cr.

\begin{tabular}{|c|c|c|c|c|c|}
\hline & \multirow{2}{*}{$\begin{array}{l}\text { Added per sample } \\
\quad\left(\mu \mathrm{g} \cdot \mathrm{mL}^{-1}\right)\end{array}$} & \multicolumn{3}{|c|}{ Intra-day $(\mathrm{n}=5)$} & \multirow[b]{2}{*}{ Inter-day ( $\mathrm{n}=3$} \\
\hline & & Day 1 & Day 2 & Day 3 & \\
\hline \multirow[t]{3}{*}{ ADMA } & 1.00 & $1.05 \pm 0.01$ & $0.95 \pm 0.01$ & $0.95 \pm 0.01$ & $0.98 \pm 0.06$ \\
\hline & 5.00 & $5.45 \pm 0.05$ & $5.45 \pm 0.04$ & $5.15 \pm 0.05$ & $5.35 \pm 0.17$ \\
\hline & 25.0 & $27.0 \pm 0.20$ & $25.3 \pm 0.20$ & $24.9 \pm 0.25$ & $25.7 \pm 1.12$ \\
\hline \multirow[t]{3}{*}{ SDMA } & 1.00 & $1.10 \pm 0.01$ & $0.95 \pm 0.02$ & $0.95 \pm 0.01$ & $1.00 \pm 0.09$ \\
\hline & 5.00 & $5.65 \pm 0.05$ & $5.60 \pm 0.05$ & $5.85 \pm 0.05$ & $5.70 \pm 0.13$ \\
\hline & 25.0 & $27.1 \pm 0.20$ & $25.5 \pm 0.20$ & $25.9 \pm 0.25$ & $26.1 \pm 0.83$ \\
\hline \multirow[t]{3}{*}{ Arg } & 1.00 & $0.90 \pm 0.49$ & $0.90 \pm 0.32$ & $0.90 \pm 0.30$ & $0.90 \pm 0.01$ \\
\hline & 5.00 & $4.75 \pm 0.06$ & $4.90 \pm 0.09$ & $4.55 \pm 0.06$ & $4.73 \pm 0.18$ \\
\hline & 25.0 & $25.2 \pm 0.26$ & $25.1 \pm 0.35$ & $24.3 \pm 0.48$ & $24.9 \pm 0.49$ \\
\hline \multirow[t]{3}{*}{$\mathrm{Cr}$} & 1.00 & $1.00 \pm 0.04$ & $1.00 \pm 0.06$ & $1.05 \pm 0.04$ & $1.02 \pm 0.03$ \\
\hline & 5.00 & $5.05 \pm 0.15$ & $5.10 \pm 0.14$ & $4.90 \pm 0.15$ & $5.02 \pm 0.10$ \\
\hline & 25.0 & $22.1 \pm 0.15$ & $23.3 \pm 0.43$ & $23.1 \pm 0.60$ & $22.8 \pm 0.64$ \\
\hline
\end{tabular}

Table 4. Precision of determination method for ADMA, SDMA, Arg and Cr.

\begin{tabular}{|c|c|c|c|c|c|}
\hline & \multirow{2}{*}{$\begin{array}{c}\text { Added per sample } \\
\left(\mu \mathrm{g} \cdot \mathrm{mL}^{-1}\right)\end{array}$} & \multicolumn{3}{|c|}{ Intra-day $(\mathrm{n}=5)$} & \multirow{2}{*}{ Inter-day $(\mathrm{n}=3)$} \\
\hline & & Day 1 & Day 2 & Day 3 & \\
\hline \multirow{3}{*}{ ADMA } & 1.00 & $0.19 \%$ & $1.02 \%$ & $0.87 \%$ & $6.32 \%$ \\
\hline & 5.00 & $0.88 \%$ & $0.66 \%$ & $0.86 \%$ & $2.98 \%$ \\
\hline & 25.0 & $0.69 \%$ & $0.80 \%$ & $0.93 \%$ & $4.20 \%$ \\
\hline \multirow{3}{*}{ SDMA } & 1.00 & $0.28 \%$ & $1.36 \%$ & $1.11 \%$ & $7.36 \%$ \\
\hline & 5.00 & $1.00 \%$ & $0.82 \%$ & $0.99 \%$ & $2.86 \%$ \\
\hline & 25.0 & $0.79 \%$ & $0.86 \%$ & $1.09 \%$ & $4.02 \%$ \\
\hline \multirow{2}{*}{ Arg } & 1.00 & $5.84 \%$ & $3.08 \%$ & $3.30 \%$ & $1.66 \%$ \\
\hline & 5.00 & $1.22 \%$ & $1.85 \%$ & $1.02 \%$ & $0.43 \%$ \\
\hline \multirow{4}{*}{$\mathrm{Cr}$} & 25.0 & $0.97 \%$ & $1.35 \%$ & $1.99 \%$ & $0.49 \%$ \\
\hline & 1.00 & $3.53 \%$ & $6.16 \%$ & $3.52 \%$ & $1.43 \%$ \\
\hline & 5.00 & $3.40 \%$ & $2.58 \%$ & $3.02 \%$ & $0.43 \%$ \\
\hline & 25.0 & $1.10 \%$ & $1.86 \%$ & $2.52 \%$ & $0.74 \%$ \\
\hline
\end{tabular}

ADMA and SDMA using a silica column [20]. Thus, additional conditions of the mobile phase were tested to obtain better retention and separation of ADMA and
SDMA.

Using either $\mathrm{MeOH}$ or $\mathrm{CH}_{3} \mathrm{CN}$ as the mobile phase did not result in a good separation of ADMA and SDMA. 
Table 5. Value of ADMA, SDMA, Arg, Cr and ADMA/SDMA in biological samples $(n=3)$.

\begin{tabular}{|c|c|c|c|c|c|}
\hline Biological samples & ADMA & SDMA & Arg & $\mathrm{Cr}$ & ADMA/SDMA \\
\hline plasma $\left(\mu g \cdot \mathrm{mL}^{-1}\right)$ & $0.289 \pm 0.031$ & $0.047 \pm 0.004$ & $15.4 \pm 0.3$ & $0.795 \pm 0.060$ & $6.13 \pm 0.11$ \\
\hline urine $\left(\mu \mathrm{g} \cdot \mathrm{mL}^{-1}\right)$ & $43.0 \pm 8.4$ & $12.4 \pm 1.8$ & $27.2 \pm 20.7$ & $553 \pm 109$ & $3.48 \pm 0.63$ \\
\hline (mg/mgCr) & $0.085 \pm 0.012$ & $0.023 \pm 0.007$ & $0.046 \pm 0.03$ & & \\
\hline brain $\left(\mu g \cdot \mathrm{mL}^{-1}\right)$ & $0.207 \pm 0.026$ & $0.113 \pm 0.011$ & $39.9 \pm 0.4$ & $96.7 \pm 2.4$ & $1.86 \pm 0.40$ \\
\hline heart $\left(\mu \mathrm{g} \cdot \mathrm{mL}^{-1}\right)$ & $1.17 \pm 0.83$ & $0.069 \pm 0.047$ & $34.6 \pm 0.4$ & $110 \pm 30$ & $17.6 \pm 0.16$ \\
\hline kidney $\left(\mu \mathrm{g} \cdot \mathrm{mL}^{-1}\right)$ & $10.4 \pm 0.3$ & $0.485 \pm 0.122$ & $142 \pm 9$ & $9.27 \pm 1.96$ & $22.3 \pm 5.5$ \\
\hline liver $\left(\mu \mathrm{g} \cdot \mathrm{mL}^{-1}\right)$ & $7.50 \pm 1.3$ & $0.596 \pm 0.224$ & $3.91 \pm 1.27$ & $4.04 \pm 0.27$ & $13.4 \pm 3.8$ \\
\hline $\operatorname{lung}\left(\mu \mathrm{g} \cdot \mathrm{mL}^{-1}\right)$ & $0.977 \pm 0.256$ & $0.047 \pm 0.016$ & $22.6 \pm 6.8$ & $4.92 \pm 1.56$ & $21.4 \pm 2.9$ \\
\hline pancreas $\left(\mu g \cdot \mathrm{mL}^{-1}\right)$ & $3.14 \pm 0.91$ & $0.237 \pm 0.088$ & $129 \pm 116$ & $37.8 \pm 6.9$ & $13.6 \pm 1.5$ \\
\hline spleen $\left(\mu \mathrm{g} \cdot \mathrm{mL}^{-1}\right)$ & $33.3 \pm 4.71$ & $1.30 \pm 0.36$ & $168 \pm 14$ & $7.48 \pm 1.26$ & $26.1 \pm 3.4$ \\
\hline
\end{tabular}

Retention in $\mathrm{MeOH}$ was much shorter than in $\mathrm{CH}_{3} \mathrm{CN}$ because of interactions of ADMA and SDMA with the silica column was stronger in $\mathrm{MeOH}$ than in $\mathrm{CH}_{3} \mathrm{CN}$. Although the Rs value increased depending on the percentage of $\mathrm{MeOH}$, all of the peaks had poor shapes due to tailing (data not shown). On the other hand, using a mixture of $\mathrm{MeOH}$ and $\mathrm{CH}_{3} \mathrm{CN}$ rather than $\mathrm{MeOH}$ or $\mathrm{CH}_{3} \mathrm{CN}$ alone resulted in better separation, retention and peak shapes. In fact, $45 \%$ of $\mathrm{CH}_{3} \mathrm{CN}$ produced the best retention and Rs value ( $\mathrm{Rs}=1.62)$. Because of hydrophilic interactions, the distribution of ADMA and SDMA between the silica column and $\mathrm{MeOH}$ was too weak and $\mathrm{CH}_{3} \mathrm{CN}$ was too strong. Thus, a mixture of $\mathrm{MeOH}$ and $\mathrm{CH}_{3} \mathrm{CN}$ results in the best retention and separation of ADMA and SDMA. Furthermore, retention time is important for high-throughput analysis. In $45 \%$ of $\mathrm{CH}_{3} \mathrm{CN}$, retention time was significantly increased for both $\mathrm{AD}$ MA and SDMA due to the strong hydrophobicity of $\mathrm{CH}_{3} \mathrm{CN}$, which retained the targeted compounds on the silica column.

Additionally, $\mathrm{pH}$ dramatically affected the retention, separation and peak shapes. ADMA and SDMA were strongly retained at $\mathrm{pH} 5$ and over. The Rs value at $\mathrm{pH}$ 3.5 was very low $(\mathrm{Rs}=1.03)$ and the peak shapes and intensity were worse at $\mathrm{pH} 4.5$ and over. The flow rate was determined from the Rs value of ADMA and SDMA. The optimal Rs value was 1.5 at a flow rate of $400 \mu \mathrm{L} \cdot \mathrm{min}^{-1}$. The best retention, separation and peak shapes were achieved at $\mathrm{pH} 4$ and a flow rate of 400 $\mu \mathrm{L} \cdot \mathrm{min}^{-1}$. These results indicate that the optimal mobile phase consists of $10 \quad \mathrm{mM} \quad \mathrm{CH}_{3} \mathrm{COONH}_{4}$ $\mathrm{H}_{2} \mathrm{O} / \mathrm{MeOH} / \mathrm{CH}_{3} \mathrm{CN}(20 / 35 / 45$, v/v) adjusted to $\mathrm{pH} 4$ using $\mathrm{CH}_{3} \mathrm{COOH}$. Separations were performed on a Mightysil Si (250 mm $\times 2$ mm I.D., $5 \mu \mathrm{m}$ particle size) analytical column coupled with a CAPCELL PAK C18 MG II (10 mm $\times 2$ mm I.D., $3 \mu \mathrm{m}$ particle size) (Shiseido, Tokyo, Japan) guard column maintained at $40^{\circ} \mathrm{C}$. A valve was used to divert the LC effluent to waste during the first $4 \mathrm{~min}$ and last $0.5 \mathrm{~min}$ of the chromatographic run. Typical chromatograms of aqueous standard solutions are shown in Figure 4. The retention times of ADMA, SDMA, Arg, Cr, IS1 and IS2 were 13.1, 12.0, 9.2, 5.1, 9.2 and $5.1 \mathrm{~min}$, respectively.

\subsection{Limit of quantification (LLOQ) and lower limit of detection (LLOD)}

The lower limit of quantification (LLOQ) was considered as the lowest concentration that was measurable with a $\mathrm{CV}$ of $>20$ and a signal-to-noise $(\mathrm{S} / \mathrm{N})$ ratio of $>10$. The lower limit of detection (LLOD) was defined as the concentration with an S/N of 3. The analytical procedure was sensitive with LLOQ and LLOD values for ADMA, SDMA, Arg and Cr of 2.47, 2.47, 2.87 and 4.42 $\mu \mathrm{mol} \cdot \mathrm{L}^{-1}$ and $0.742,0.742,0.862$ and $1.33 \mu \mathrm{mol} \cdot \mathrm{L}^{-1}$, respectively. The LLOD values obtained using our methodology were similar to those previously reported for ADMA and SDMA determination in biological samples [23]. However, the previously reported methodology required $100 \mu \mathrm{L}$ of plasma, whereas our methodology required only $10 \mu \mathrm{L}$ of plasma and $1 \mu \mathrm{L}$ of urine. These results suggest that the sensitivity of our novel methodology was 10 -fold greater than the previously reported methodology.

\subsection{Linearity}

The linearity of the calibration curves was evaluated using seven concentrations $(0.250,0.500,1.00,2.50,5.00$, 25.0 and $50.0 \mu \mathrm{g} \cdot \mathrm{mL}^{-1}$ ). The calibration curves of ADMA, SDMA, Arg and Cr were all linear over a range of 0.500 - $50.0 \mu \mathrm{g} \cdot \mathrm{mL}^{-1}$ (2.47 - 247, 2.47 - 247, 2.87 - 287 and 4.42 - $442 \mu \mathrm{mol} \cdot \mathrm{L}^{-1}$, respectively) (Table 2). A linear regression analysis was performed on these portions 
of the curves, and it was found that the correlation coefficient was greater than 0.999 for all analytes.

\subsection{Accuracy and precision}

The results for the accuracy and precision are shown in Tables 3 and 4, respectively. The intra- and inter-day accuracies ranged from $86.9 \%$ to $112 \%$ for the three concentrations used with all of the compounds. The intra- and inter-day precisions ranged from $0.19 \%$ to $7.36 \%$ for the three concentrations used with all of the compounds. These results indicate that our methodology has good reliability and repeatability. Validation was determined by spiking the standard compounds in plasma. Generally, validation of analytical methods is necessary, since the effects of ion suppression are variable in different types of tissues, and this is achieved by spiking each tissue sample. In our methodology, matrix effects could be avoided by using a silica column and the optimal mobile phase, which allows for chromatographic separation of ADMA and SDMA in several biological

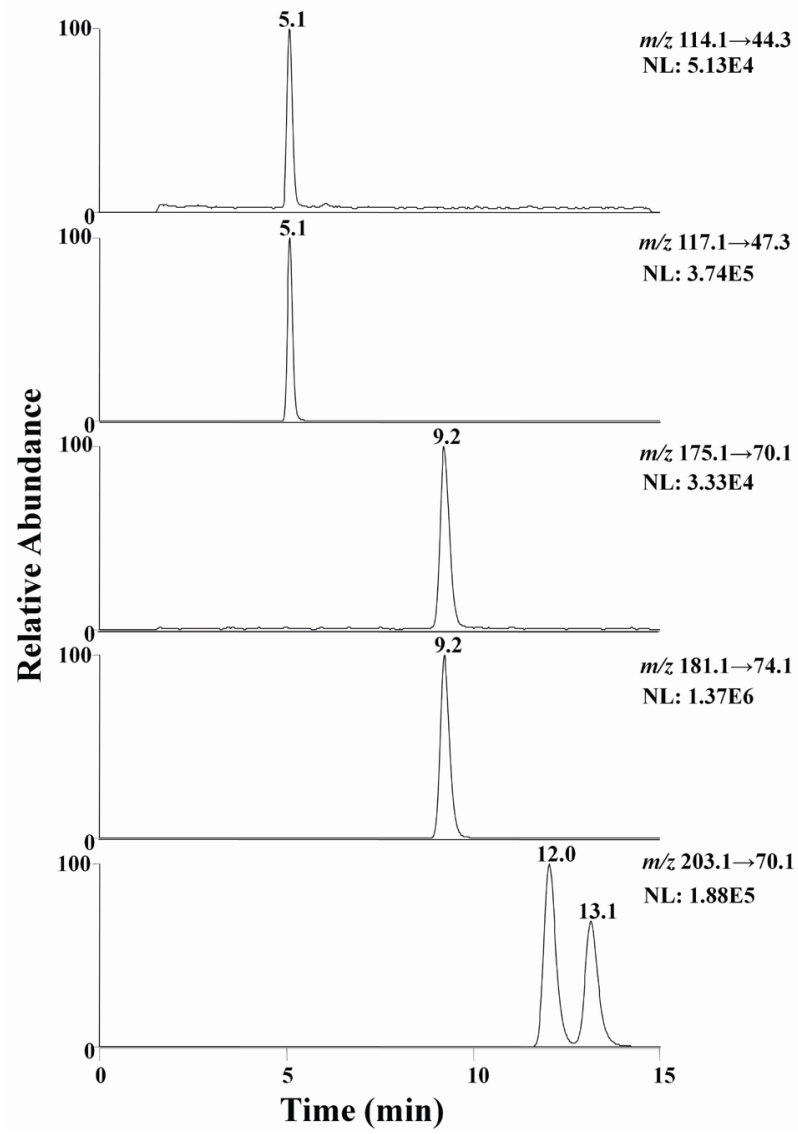

Figure 4. SRM chromatograms of $m / z \quad 114.1 \rightarrow 44.3$ for $C r$, $\mathrm{m} / \mathrm{z} \quad 117.1 \rightarrow 47.3$ for $\mathrm{Cr}-\mathrm{d}_{3}, \mathrm{~m} / \mathrm{z} \quad \mathbf{1 7 5 . 1} \rightarrow \mathbf{7 0 . 1}$ for Arg, $\mathrm{m} / \mathrm{z}$ 181.1 $\rightarrow 74.1$ for $\operatorname{Arg}-{ }^{13} C_{6}$ and $m / z$ 203.1 $\rightarrow 70.1$ for ADMA and SDMA from standard compounds. samples.

\subsection{Tissue distribution of ADMA and SDMA in BALBc/J mice}

ADMA, SDMA, Arg and Cr levels determined from various tissue samples of mice are shown in Table 5 . Although, all compounds were detected, some samples contained analytes at concentration levels outside the linear working range. These samples were adjusted into the working range of the calibration and were reanalyzed. The SRM chromatograms of biological sample are shown in Figure 5. ADMA and SDMA levels were high in urine, kidneys, liver, pancreas and spleen. With the exception of low liver levels, Arg had similar urine and tissue levels as ADMA and SDMA. Cr levels were high in plasma, urine, brain, heart and pancreas. In previous studies, Arg/ADMA or ADMA + SDMA/monomethylarginine (MMA) ratios were described to have an important role evaluating disease progression [27]. Therefore, we calculated ADMA/SDMA ratios for tissue comparisons (Table 5). ADMA/SDMA ratios in the brain

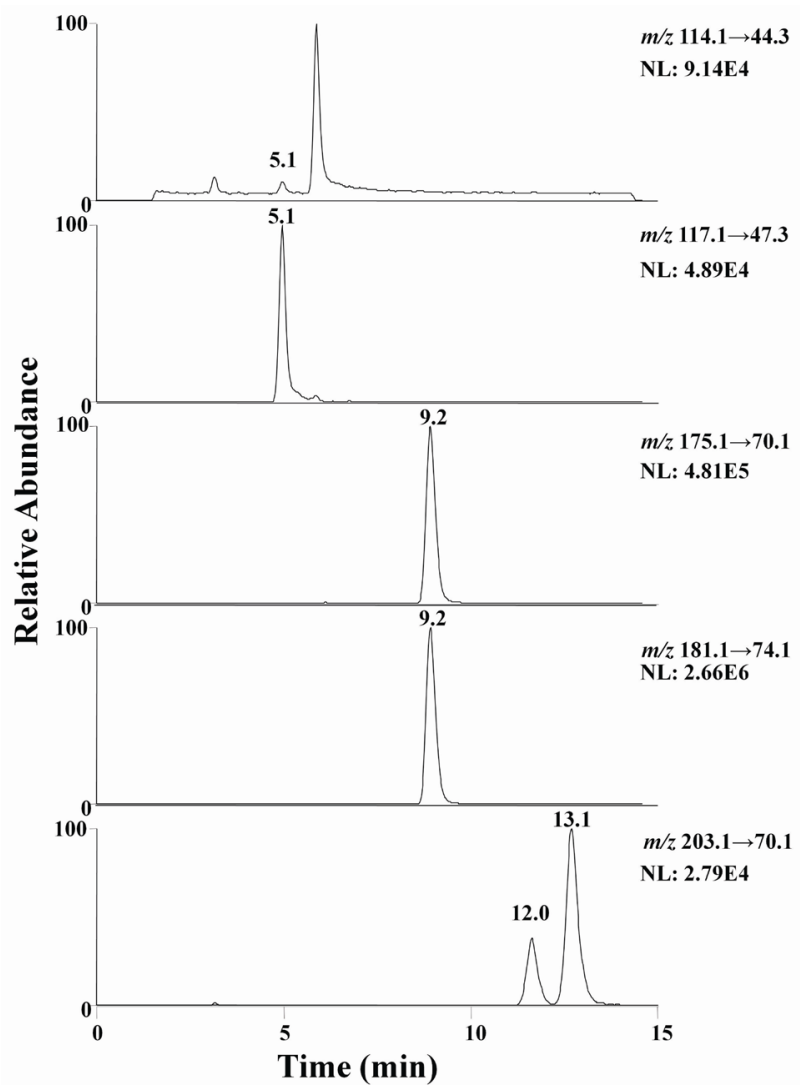

Figure 5. SRM chromatograms of $m / z \quad 114.1 \rightarrow 44.3$ for $\mathrm{Cr}$, $\mathrm{m} / \mathrm{z} \quad 117.1 \rightarrow 47.3$ for $\mathrm{Cr}-\mathrm{d}_{3}, \mathrm{~m} / \mathrm{z} \quad 175.1 \rightarrow 70.1$ for Arg, $\mathrm{m} / \mathrm{z}$ 181.1 $\rightarrow$ 74.1 for $\operatorname{Arg}-{ }^{13} C_{6}$ and $m / z$ 203.1 $\rightarrow 70.1$ for ADMA and SDMA from a biological sample (plasma). 
and plasma were lower than in the other tissues. The present study is the first to demonstrate lower level of ADMA/SDMA in the brain. DDAH is an enzyme that is known to metabolize endogenous nitric oxide synthase (NOS) inhibitors such as MMA and ADMA to citrulline [28]. The gene expression of DDAH I and II has been reported by Tra et al., and DDAH I have been more distributed in the brain than the other organs [29]. In addition, DDAH I and NOS were up-regulated in neurons following nerve injury [30]. These reports indicated that ADMA might be expeditiously metabolized by DDAH I in the brain, and the central nerves system might be protected by the low concentration of ADMA from the affection of NOx via the inhibition with NOS. Although the reason and mechanism for these findings cannot be elucidated in the present study, the data suggests that the brain and plasma may have high levels of SDMA in relation to ADMA. It has been suggested that the relative value is just as important as the absolute value for revealing the mechanisms of ADMA and SDMA. Thus, our novel methodology proved to be useful in detecting ADMA and SDMA in various biological samples with high sensitivity and selectivity.

\section{Concluding remarks}

We have developed a methodology for ADMA and SDMA determination in biological samples using LC/ MS/MS. Furthermore, it was validated that this methodology can determine ADMA and SDMA levels with high sensitivity and reliability. This methodology is the first of its kind that can determine tissue distribution of ADMA and SDMA with good separation. Additionally, this methodology requires small sample sizes, specifically only $10 \mu \mathrm{L}$ of plasma, $1 \mu \mathrm{L}$ of urine and about 25 mg of tissues were required in the present study. Furthermore, the ADMA/SDMA ratio was found to be lower in the brain than in any other tissues. Although the mechanism for this finding is unclear, the developed methodology was useful in determining ADMA and SDMA levels in biological samples.

\section{References}

[1] A. J. Pope, K. Karuppiah and A. J. Cardounel, "Role of the PRMT-DDAH-ADMA axis in the Regulation of Endothelial Nitric Oxide Production,” Pharmacological Reserch, Vol. 60, No. 6, 2009, pp. 461-465. doi:10.1016/j.phrs.2009.07.016

[2] C. Y. Ivashchenko, B. T. Bradley, Z. H. Ao, J. Leiper, P. Vallance and D. G. Johns, "Regulation of the ADMADDAH System in Endothelial Cells: A Novel Mechanism for the Sterol Response Element Binding Proteins, SREBP1c and-2," American Journal of Physiology-Heart and Circulatory Physiology, Vol. 298, 2010, pp. 251-258. doi:10.1152/ajpheart.00195.2009

[3] F. Kronenberg, "Emerging Risk Factors and Markers of Chronic Kidney Disease Progression,” Nature Reviews Nephrology, Vol. 5, 2009, pp. 677-689. doi:10.1038/nrneph.2009.173

[4] J. T. Kielstein, D. Fliser and H. Veldink, “Asymmetric Dimethylarginine and Symmetric Dimethylarginine: Axis of Evil or Useful Alliance?” Seminars in Dialysis, Vol. 22, No. 5, 2009, pp. 346-350. doi:10.1038/nrneph.2009.173

[5] L. Tarnow, P. Hovind, T. Teerlink, C. D. A. Stehouwer and H. H. Parving, "Elevated Plasma Asymmetric Dimethylarginine as a Marker of Cardiovascular Morbidity in Early Diabetic Nephropathy in Type 1 Diabetes," Diabetes Care, Vol. 27, No. 3, 2004, pp. 765-769. doi:10.2337/diacare.27.3.765

[6] S. Abhary, N. Kasmeridis, K. P. Burdon, A. Kuot, M. J. Whiting, W. P. Yew, N. Petrovsky and J. E. Craig, "Diabetic Retinopathy is Associated With Elevated Serum Asymmetric and Symmetric Dimethylarginines," Diabetes Care, Vol. 32, No. 11, 2009, pp. 2084-2086. doi:10.2337/dc09-0816

[7] T. Toyohara, T. Suzuki, R. Morimoto, Y. Akiyama, T. Souma, H. O. Shiwaku, Y. Takeuchi, E. Mishima, M. Abe, M. Tanemoto, S. Masuda, H. Kawano, K. Maernura, M. Nakayama, H. Sato, T. Mikkaichi, H. Yamaguchi, S. Fukui, Y. Fukumoto, H. Shimokawa, K. Inui, T. Terasaki, J. Goto, S. Ito, T. Hishinuma, I. Rubera, M. Tauc, Y. Fujii-Kuriyama, H. Yabuuchi, Y. Moriyama, T. Soga and T. Abe, "SLCO4C1 Transporter Eliminates Uremic Toxins and Attenuates Hypertension and Renal Inflammation," Journal of the American Society of Nephrology, Vol. 20, 2009, pp. 2546-2555. doi:10.1681/ASN.2009070696

[8] J. T. Kielstein, R. H. Boger, S. M. Bode-Boger, J. Schaffer, M. Barbey, K. M. Koch and J. C. Frolich, "Asymmetric Dimethylarginine Plasma Concentrations Differ in Patients with End-Stage Renal Disease: Relationship to Treatment Method and Atherosclerotic Disease,” Journal of the American Society of Nephrology, Vol. 10, 1999, pp. 594-600.

[9] E. Schwedhelm, R. Maas, J. Tan-Andresen, F. Schulze, U. Riederer and R. H. Boger, "High-Throughput Liquid Chromatographic-Tandem Mass Spectrometric Determination of Arginine and Dimethylated Arginine Derivatives in Human and Mouse Plasma,” Journal of Chromatography B-Analytical Technologies in the Biomedical and Life Sciences, Vol. 851, No. 1-2, 2007, pp. 211-219. doi:10.1016/j.jchromb.2006.11.052

[10] F. Schulze, R. Wesemann, E. Schwedhelm, K. Sydow, J. Albsmeier, J. P. Cooke and R. H. Boger, "Determination of Asymmetric Dimethylarginine (ADMA) Using a Novel ELISA Assay," Clinical Chemistry and Laboratory Medicine, Vol. 42, No. 12, 2004, pp. 1377-1383. doi:10.1515/CCLM.2004.257

[11] A. Zinellu, S. Sotgia, E. Zinellu, A. Pinna, F. Carta, L. Gaspa, L. Deiana and C. Carru, "High-Throughput CZEUV Determination of Airginine and Dimethylated Argi- 
nines in Human Plasma,” Electrophoresis, Vol. 28, No. 12, 2007, pp. 1942-1948. doi:10.1002/elps.200600534

[12] N. Rawal, Y. J. Lee, J. N. Whitaker, J. O. Park, W. K. Paik and S. Kim, "Urinary-Excretion of N-G-Dimethylarginines in Multiple-Sclerosis Patients-Preliminary-Ob- servations," Journal of the Neurological Sciences, Vol. 129, No. 2, 1995, pp. 186-191. doi:10.1016/0022-510X(94)00277-U

[13] S. Sotgia, A. Zinellu, G. A. Pinna, L. Deiana and C. Carru, "A New Selective Pre-Column Ninhydrin-Based Derivatization for a RP-HPLC Determination of Plasma Asymmetric Dimethyl-L-Arginine (ADMA) by Fluorescence Detection," Amino Acids, Vol. 34, No. 4, 2008, pp. 677-682. doi:10.1007/s00726-007-0001-X

[14] Y. Ohike, K. Kozaki, K. Iijima, M. Eto, T. Kojima, E. Ohga, T. Santa, K. Imai, M. Hashimoto, M. Yoshizumi and Y. Ouchi, "Amelioration of Vascular Endothelial Dysfunction in Obstructive Sleep Apnea Syndrome by Nasal Continuous Positive Airway Pressure-Possible Involvement of Nitric Oxide and Asymmetric NG, NGDimethylarginine,” Circulation Journal, Vol. 69, No. 2, 2005, pp. 221-226. doi:10.1253/circj.69.221

[15] Y. Dobashi, T. Santa, K. Nakagomi and K. Imai, “An Automated Analyzer for Methylated Arginines in Rat Plasma by High-Performance Liquid Chromatography with Postcolumn Fluorescence Reaction," Analyst, Vol. 127, No. 1, 2002, pp. 54-59. doi:10.1039/b106828h

[16] K. Vishwanathan, R. L. Tackett, J. T. Stewart and M. G. Bartlett, "Determination of Arginine and Methylated Arginines in Human Plasma by Liquid ChromAtography-Tandem Mass Spectrometry," Journal of Chromatography B, Vol. 748, No. 1, 2000, pp. 157-166. doi:10.1016/S0378-4347(00)00399-6

[17] R. Maas, J. Tan-Andreesen, E. Schwedlhelm, F. Schulze and R. H. Boger, "A Stable-Isotope Based Technique for the Determination of Dimethylarginine DimethylaminoHydrolase (DDAH) Activity in Mouse Tissue,” Journal of Chromatography B, Vol. 851, No. 1-2, 2007, pp. 693701. doi:10.1016/j.jchromb.2007.01.020

[18] M. J. Bishop, B. Crow, D. Norton, E. Paliakov, J. George and J. A. Bralley, "Direct Analysis of Un-Derivatized Asymmetric Dimethylarginine (ADMA) and L-Arginine from Plasma Using Mixed-Mode Ion-Exchange Liquid Chromatography-Tandem Mass Spectrometry,” Journal of Chromatography B-Analytical Technologies in the Biomedical and Life Sciences, Vol. 859, No. 2, 2007, pp. 164-169. doi:10.1016/j.jchromb.2007.09.024

[19] M. Zotti, S. Schiavone, F. Tricarico, M. Colaianna, O. D'Apolito, G. Paglia, G. Corso and L. Trabace, "Determination of Dimethylarginine Levels in Rats Using HILIC- MS/MS: An in Vivo Microdialysis Study," Journal of Separation Science, Vol. 31, 2008, pp. 2511-2515. doi:10.1002/jssc.200800147

[20] G. Paglia, O. D'Apolito, F. Tricarico, D. Garofalo and G. Corso, "Evaluation of Mobile Phase, Ion Pairing, and Temperature Influence on an HILIC-MS/MS Method for L-Arginine and its Dimethylated Derivatives Detection," Journal of Separation Science, Vol. 31, No. 13, 2008, pp.

\section{4-2429. doi:10.1002/jssc.200800142}

[21] I. M. Di Gangi, L. Chiandetti, A. Gucciardi, V. Moret, M. Naturale and G. Giordano, "Simultaneous Quantitative Determination of N-G,N-G-Dimethyl-L-Arginine or Asymmetric Dimethylarginine and Related Pathway's Metabolites in Biological Fluids by Ultrahigh-Performance Liquid Chromatography/Electrospray Ionization-Tandem Mass Spectrometry,” Analytica Chimica Acta, Vol. 677, No. 2, 2010, pp. 140-148. doi:10.1016/j.aca.2010.08.011

[22] C. Desiderio, D. V. Rossetti, I. Messana, B. Giardina and M. Castagnola, "Analysis of Arginine and Methylated Metabolites in Human Plasma by Field Amplified Sample Injection Capillary Electrophoresis Tandem Mass Spectrometry," Electrophoresis, Vol. 31, No. 11, 2010, pp. 1894-1902. doi:10.1002/elps.200900690

[23] A. Zinellu, S. Sotgia, M. F. Usai, G. Pintus, L. Deiana and C. Carru, "Improved Method for Plasma ADMA, SDMA, and Arginine Quantification by Field-Amplified Sample Injection Capillary Electrophoresis UV Detection,” Analytical and Bioanalytical Chemistry, Vol. 23, 2010.

[24] D. Saigusa, N. Suzuki, M. Takahashi, K. Shiba, S. Tanaka, T. Abe, T. Hishinuma and Y. Tomioka, "Simultaneous Determination of Guanidinosuccinic Acid and Guanidinoacetic Acid in Urine Using High Performance Liquid Chromatography/Tandem Mass Spectrometry,” Analytica Chimica Acta, Vol. 677, No. 2, 2010, pp. 169- 175. doi:10.1016/j.aca.2010.08.005

[25] A. Nakajima, D. Saigusa, N. Tetsu, T. Yamakuni, Y. Tomioka and T. Hishinuma, "Neurobehavioral effects of tetrabromobisphenol A, a brominated flame retardant, in mice,” Toxicology Letters, Vol. 189, No. 1, 2009, pp. 7883. doi:10.1016/j.toxlet.2009.05.003

[26] J. Martens-Lobenhoffer, E. Schwedhelm and D. Tsikas, "Quantification of Arginine and its Mono- and Dimethylated Analogs NMMA, ADMA and SDMA in Biological Fluids by LC-MS/MS: Is LC superfluous?” Journal of chromatography B, Analytical technologies in the biomedical and life sciences, Vol. 877, No. 27, 2009, pp. 3261-3266. doi:10.1016/j.jchromb.2009.07.003

[27] Z. Ajtay, A. Nemeth, E. Sulyok, A. Cziraki, S. Szabados, J. Martens-Lobenhoffer, F. Awiszus, C. Szabo and S. M. Bode-Boger, "Effects of Stent Implementation on Plasma Levels of Asymmetric Dimethylarginine in Patients with or without ST-Segment Elevation Acute Myocardial Infarction," International Journal of Molecular Medicine, Vol. 25, No. 4, 2010, pp. 617-624.

[28] M. Kimoto, G. S. Whitley, H. Tsuji and T. Ogawa, "Detection of NG, NG-Dimethylarginine Dimethylaminohidrolase in Human Tissues Using a Monoclonal Antibody," Journal of Biochamistry, Vol. 117, No. 2, 1995, pp. 237-238. doi:10.1093/jb/117.2.237

[29] C.T.L. Tran, M.F. Fox, P. Vallance, and J. M. Leiper, "Chromosomal Localozation, Gene Structure, and Expression Pattern of DDAH1: Comparison with DDAH2 and Implications for Evolutionary Origins," Genomics, Vol. 68, No. 1, 2000, pp. 101-105.

doi:10.1006/geno.2000.6262 
[30] S. Nakagomi, S. Kiryu-Seo, M. Kimoto, P. C. Emson and H. Kiyama, "Dimethylarginine Dimethylaminohidrolase (DDAH) as a Nerve-Injury-Associated Molecule: mRNA Localozation with Neuronal NO Synthase (nNOS) in
Axotomizwd Motoneurons," European Journal of Neuroscience, Vol. 11, No. 6, 1999, pp. 2160-2166.

doi:10.1046/j.1460-9568.1999.00634.X 